Scientific Electronic Archives

Issue ID: Sci. Elec. Arch. Vol. 14 (12)

December 2021

DOI: http://dx.doi.org/10.36560/141220211481

Article link: https://sea.ufr.edu.br/SEA/article/view/1481

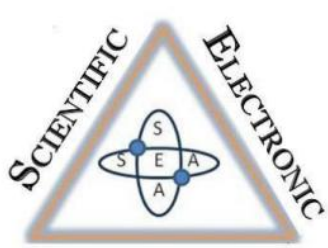

Archives

ISSN 2316-9281

\title{
Uso de semioquímicos no controle de lepidópteros
}

\author{
Use of semiochemicals in lepidopteran control
}

Corresponding author

Heloisa Martins de Araújo

Universidade Federal da Paraíba-Centro de Ciências Agrárias

heloiisa.martiins@gmail.com

Jacinto de Luna Batista
Universidade Federal da Paraíba-Centro de Ciências Agrárias

Letícia Barbosa de Lacerda

Universidade Federal da Paraíba-Centro de Ciências Agrárias

José Rayan Eraldo de Souza Araújo

Universidade Federal da Paraíba-Centro de Ciências Agrárias

Paulo Henrique de Almeida Cartaxo

Universidade Federal da Paraíba-Centro de Ciências Agrárias

João Henrique Barbosa da Silva

Universidade Federal da Paraíba-Centro de Ciências Agrárias

Erisvaldo de Souza Buriti

Universidade Federal da Paraíba-Centro de Ciências Agrárias

Kennedy Santos Gonzaga

Universidade Federal da Paraíba-Centro de Ciências Agrárias

Gemerson Machado de Oliveira

Universidade Federal da Paraíba-Centro de Ciências Agrárias

João Paulo de Oliveira Santos

Universidade Federal da Paraíba-Centro de Ciências Agrárias

\begin{abstract}
Resumo. O ataque de insetos-praga causa perdas substanciais na produção agrícola. Dentre esses insetos, destacamse os pertencentes à ordem Lepidoptera. Para o controle desses organismos se faz uso principalmente de inseticidas, porém, em busca de uma produção sustentável e limpa, o desenvolvimento de novos produtos de controle são desejáveis, como por exemplo, o uso de semioquímicos. Nesse sentido, esse estudo objetivou revisar o conhecimento atual sobre semioquímicos, destacando as possibilidades do uso destes compostos como uma alternativa para implementação nos programas de manejo integrado destes insetos-pragas, destacando o conhecimento atual e identificando tendências futuras. Os semioquímicos são compostos químicos utilizados pelos insetos como meio de comunicação para exercício de suas relações ecológicas. Dependendo da relação com a espécie do emissor e do receptor do sinal químico, e de acordo com os resultados decorrentes desta comunicação, esses compostos podem ser classificados em feromônios e aleloquímicos. Os semioquímicos podem ser empregados no monitoramento, captura,
\end{abstract}


redução no índice de oviposição, mortalidade de ovos e confusão sexual em lepidópteros. Mostrando-se assim, como uma ferramenta promissora no controle dos insetos-praga dessa ordem.

Palavras-chave: Aleloquímicos, feromônios, manejo integrado de pragas.

\begin{abstract}
The attack of pest insects causes substantial losses in agricultural production. Among these insects, those belonging to the order Lepidoptera stand out. For the control of these organisms, insecticides are used mainly, however, in search of a sustainable and clean production, the development of new control products is desirable, such as the use of semiochemicals. In this sense, this study aimed to review the current knowledge about semiochemicals, highlighting the possibilities of using these compounds as an alternative for implementation in integrated management programs for these insect pests, highlighting current knowledge and identifying future trends. Semiochemicals are chemical compounds used by insects as a means of communication to exercise their ecological relationships. Depending on the relationship with the species of the chemical signal emitter and receiver, and according to the results resulting from this communication, these compounds can be classified into pheromones and allelochemicals. Semiochemicals can be used to monitor, capture, reduce the oviposition rate, egg mortality and sexual confusion in lepidopterans. Thus, showing itself as a promising tool in the control of insect pests of this order.
\end{abstract}

Keywords: Allelochemicals, pheromones, integrated pest management.

\section{Introdução}

Os insetos da ordem Lepidoptera são holometabólicos e seu ciclo de vida apresenta o estágio de ovo, lagarta, pupa ou crisália e adultos. Quando lagartas, apresentam corpo mole, alongado, recoberto de cerdas, podendo apresentar-se com tamanho e formas variáveis, o aparelho bucal é do tipo mastigador, o que ocasiona danos diretos as plantas, podem ser roedores de raízes e região do colo, devoradores de folhas e hastes, minadoras de folhas ou broqueadoras de bulbos e ramos. Alimentam-se constantemente até atingir a fase de pupa, e quando posteriormente tornam-se adultos, são prejudiciais por serem fonte de infestação pela postura dos ovos que logo originará as lagartas (IMENES \& IDE, 2002).

As perdas na produção devido ao ataque de insetos são de $14 \%$ nos países desenvolvidos e $38 \%$ em países em desenvolvimento (ZAMBOLIM et al., 2008). No Brasil, as 49 principais culturas produzidas são atacadas por 447 diferentes espécies de insetos, resultando em uma média de aproximadamente 9 insetos-praga por cultura. Dentre todas as espécies, algumas destacam-se em função do impacto negativo que causam ao agronegócio, o que se deve as grandes áreas de cultivo e da quantidade diferenciada de culturas que atacam; atendendo a estes critérios, 7 das 10 principais pragas são lepidópteros (ZARBIN et al., 2009).

A constante pressão da sociedade pela produção sustentável, impõe a criação de novas tecnologias menos agressivas ao meio ambiente e à saúde humana. No controle de pragas há uma busca incessante por estratégias ecológicas que sejam capazes de implementar os programas de manejo integrado de pragas (MIP) (PINTOZEVALLOS et al., 2013).

No MIP, quando um inseto-praga é identificado no monitoramento, passa a ser denominado como 'inseto-alvo", a partir do momento que a população deste atinge o estado de "nível de dano econômico", qualquer que seja a intervenção a ser utilizada como forma de controle, deve ser pontual e estritamente necessária. No sistema de manejo integrado, são utilizadas diversas ferramentas, a exemplo do uso de variedades resistentes, monitoramento com feromônio, uso de agroquímicos específicos, plantas geneticamente modificadas, uso de predadores ou parasitóides e entomopatógenos (ZARBIN et al., 2009).

A comunicação química desempenha um papel vital para a sobrevivência dos insetos, esta é baseada sobretudo através da quimiossensibilidade. Permitindo que os indivíduos avaliem o ambiente imediato através de mudanças comportamentais, esses produtos químicos são chamados de semioquímicos (GOULART et al., 2015; RODRIGUEZ et al., 2018).

Os voláteis induzidos após o ataque dos herbívoros não só guiam os inimigos naturais em direção à planta hospedeira da presa, mas também agem na mediação de várias interações ecológicas que têm potencial para o desenvolvimento de novas estratégias de controle de pragas (DICKE \& TAKKEN, 2006).

Diante dos elevados danos que os lepidópteros podem causar as culturas e posteriormente a economia, essa estudo buscou revisar o conhecimento atual sobre semioquímicos, destacando as possibilidades do uso destes compostos como uma alternativa para implementação nos programas de manejo integrado destes insetos-pragas, destacando o conhecimento atual e identificando tendências futuras.

\section{Uso de semioquímicos no controle de lepidópteros}

\section{Caracterização e classificação}

Os semioquímicos são compostos químicos utilizados pelos insetos como meio de comunicação para exercício de suas relações ecológicas. Esses compostos agem no indivíduo receptor na forma de mensagem química nos gatilhos fisiológicos das reações comportamentais, ou seja, como intermediador de suas relações (ZARBIN et al., 2009). A detecção e emissão destes compostos são essenciais para que os indivíduos encontrem um local de oviposição na reprodução e na detecção de fontes alimentares (ZHANG et al., 2015). 
Os semioquímicos são detectados através de receptores olfativos alojados nas antenas e palpos maxilares de insetos (ZHANG et al., 2015). São classificados quanto a relação com a espécie do emissor e do receptor do sinal químico, e de acordo com os resultados decorrentes desta comunicação. São denominados de feromônios, os compostos em que o emissor e receptor do sinal químico são da mesma espécie. $E$ aleloquímicos os compostos que intermedeiam comportamentos de indivíduos de diferentes espécies (LEAL, 2005).

Os feromônios provocam uma reação específica ou processo fisiológico definido. Podendo incluir diferentes tipos de comportamento, como; sexual, agregação, dispersão, alarme, territorialidade, trilha, oviposição e outros (LUNTZ, 2003).

A denominação da subclassificação dos aleloquímicos é baseado nos resultados produzidos pela interação que foi intermediada pelo composto. Os compostos que beneficiam o indivíduo receptor recebem a denominação de cairomônios, aqueles que beneficiam o emissor de alomônios, e sinomônios quando ambos são beneficiados (ZARBIN et al., 2009).

Os apneumônios e antimônios também são considerados aleloquímicos, o primeiro são substâncias químicas emitidas por um material não vivo que desencadeia uma reação comportamental ou fisiológica adaptativamente favorável ao organismo receptor. Já o segundo, são as substâncias produzidas ou adquiridas por um organismo, que, quando em contato com indivíduo de uma espécie diferente em ambiente natural, é ativada resposta repelente entre emissores e receptores (VILELA \& DELLA LÚCIA, 2001).

\section{Ecologia química}

Os aleloquímicos são metabólitos secundários bioativos produzidos e liberados pelas plantas. Apesar das diferenças na atividade biológica, modo de liberação e ação, os compostos relacionados geralmente compartilham vias biossintéticas semelhantes, enquanto isso, algumas classes destes metabólitos podem ser produzidas a partir de diversas vias (LATIF et al., 2017). A produção dos compostos pode ser afetada por fatores abióticos e bióticos que influenciam a capacidade de defesa ou o potencial alelopático das plantas (AN et al., 2003).

Os compostos voláteis induzidos após a herbivoria são formados principalmente por aldeídos, e por álcoois $\mathrm{C} 6$ e seus ésteres, produzidos através da rota da enzima lipoxigenase e terpenoides. Os compostos derivados da rota dos octadecanóides são conhecidos como voláteis de folhas verdes e são emitidos principalmente quando as folhas são danificadas mecanicamente. Estes podem constituir mais de $50 \%$ da emissão de partes danificadas em algumas espécies de plantas (HOLOPAINEN, 2004).

Nos tecidos, com dano mecânico ou de alimentação, estes voláteis são sintetizados rapidamente, enquanto que em tecidos de plantas saudáveis e intactas a quantidade destes compostos é baixa. Confirmando o fato de que eles sejam emitidos de forma passiva pela planta (MATSUI, 2006).

Um feromônio de qualquer inseto é caracterizado por seu número de carbono, grupo funcional, arranjo de ligações duplas e proporção entre compostos maiores e menores (BAKTHAVATSALAM, 2016). Além do carbono, o hidrogênio e oxigênio compõem os átomos mais usuais incorporados as estas moléculas, embora, já tenham havido identificação de compostos nitrogenados e clorados. Geralmente, quando há necessidade de uma rápida dispersão de sinal, as moléculas utilizadas são pequenas, enquanto que, para uma longa exposição há necessidade de compostos maiores e menos voláteis, funcionando assim na atração e estimulação (TUMLINSON \& TEAL, 1987).

Além dos diferentes tamanhos moleculares que refletem as funções comportamentais, as estruturas de feromônios variam muito entre as diferentes ordens de insetos. Um mesmo composto pode ser estruturalmente relacionado por muitas espécies do mesmo gênero, pelo desenvolvimento a partir de vias biossintéticas comuns, com diferenças nos componentes de mistura e nas proporções, sendo resultado de pequenas permutações nas etapas enzimáticas envolvidas (TUMLINSON \& TEAL, 1987)

\section{Mecanismo de ação \\ Os semioquímicos são moléculas} hidrofóbicas e os receptores que eles ativam são imersos em um ambiente aquoso em várias sensilas em antenas, palpos maxilares ou probóscide. As proteínas de ligação odorantes solubilizam e transportam os semioquímicos para os neurônios que abrigam os receptores. Neste nível periférico, as informações são processadas por um híbrido de codificação combinatória e linhas rotuladas. Os receptores odorantes são diversos, estes formam canais de íons com um co-receptor chamado Orco, que também forma canais de íons por si só (LEAL, 2019).

Os metabólitos secundários tóxicos produzidos pelas plantas, aleloquímicos, são exemplos de defesa contra insetos-praga. Muitas interações intra e intraespecíficas são, pelo menos em parte, reguladas por estes compostos. As interações predador-presa são influenciadas por cairomônios, permitindo que a presa detecte quimicamente predadores e reaja por alterações comportamentais, morfológicas ou do histórico de vida, ou por sinais de alarme liberados por presas danificadas, provocando alterações comportamentais em espécies específicas. Aleloquímicos são liberados por organismos intactos ou danificados ou estão localizados no tecido e compreendem a concorrência não-exploratória entre plantas, podendo também afetar a sucessão da comunidade. Como exemplo destes compostos, 
podem ser destacados a nicotina ou furanocumarinas, que podem matar herbívoros generalistas não adaptados; e proteínas de defesa como inibidores de proteases ou polifenol oxidases que dificultam a digestão e diminuem a disponibilidade de nutrientes e consequentemente, o crescimento dos herbívoros. Esses mecanismos são considerados defesas diretas, uma vez que afetam diretamente os herbívoros ao impedir a alimentação, enquanto que nas defesas indiretas os compostos aumentam a mortalidade de herbívoros através do recrutamento de parasitóides e predadores (KESSLER \& BALDWIN, 2001; GROSS, 2009; PINTO-ZEVALLOS et al., 2013).

Feromônios são substâncias químicas utilizadas para comunicação intra-específica, enquadrando-se em diversas categorias que geralmente estão relacionadas à função que exercem. São reconhecidos através da resposta que produzem no receptor da mensagem. Os comportamentos mais comuns mediados por feromônio são: a atração de indivíduos do sexo oposto para acasalamento, denominados de feromônios sexuais; a agregação de indivíduos de ambos os sexos para um local específico para alimentação e/ou de acasalamento, através de feromônios de agregação; a demarcação de espaço ou formação de trilhas, classificados como de marcação ou trilha. Além destes, insetos sociais utilizam uma variedade de feromônios para organizar as atividades na colônia (SUCKLING, 2000; LEAL, 2005; ZARBIN, 2009).

\section{Emprego no manejo integrado de pragas}

Semioquímicos, quando empregados sozinhos, geralmente oferecem um controle de pragas ineficaz ou insuficiente, dessa forma, estes compostos devem ser combinados com outras estratégias de gestão integrada. Como por exemplo, o monitoramento das pragas para permitir um timing preciso dos tratamentos com pesticidas, uso combinado com semioquímicos, resistência de plantas hospedeiras e armadilhas para manipular o comportamento de pragas, agentes de controle biológico e uso de inseticidas seletivos quando necessário (PICKETT, 1997).

O uso da semioquímica como estratégia chave torna-se uma ferramenta promissora pelas vantagens que apresenta, incluindo a baixa poluição ou mesmo nula, custos mais baixos, especificidade e uso fácil (TEWARI, 2014). Existe ainda a oportunidade de desenvolver intervenções não tóxicas utilizando estes compostos que influenciam o comportamento dos indivíduos. Atrativos podem ser usados em armadilhas de iscas para monitoramento. Além disso, semioquímicos que repelem pragas ou atraem seus inimigos naturais podem ser usados para manter as populações causadoras de danos abaixo de níveis prejudiciais (SMART et al., 2014).

O uso de feromônio é difundido no monitoramento dos insetos, para predição da população, triagem de quarentena e dispersão. A prática de captura em massa e interrupção do acasalamento são realizadas isoladamente ou em combinação com inseticidas ou tecnologias de biocontrole. Indiretamente, esses métodos reduzem o uso de produtos químicos e facilitam a conservação de inimigos naturais (BAKTHAVATSALAM, 2016).

Os paraferomônios comuns utilizados no monitoramento, aprisionamento de massa e aniquilação masculina são o metil eugenol, cuelura e trimedlure. Os voláteis das plantas, isoladamente ou em mistura, são utilizados para aprisionar em massa vários insetos, especialmente pragas da ordem coleóptera. $\bigcirc$ uso de feromônio está difundido em lepidópteros, coleópteros, dípteros, homópteros, dentre outros. Cairomônios e sinomônios melhoram o desempenho de inimigos naturais (BAKTHAVATSALAM, 2016).

A produção de aleloquímicos integra as estratégias de defesa das plantas, de natureza química e física. Além disto, auxilia na proteção e gerenciamento das culturas, podendo também servir como fonte para o desenvolvimento e aplicação destes compostos por apresentarem princípio inseticida (LAFIT et al., 2017).

\section{Emprego no manejo de lepidópteros}

Os compostos voláteis induzidos após o ataque dos herbívoros apresentam potencial para o desenvolvimento de estratégias de controle de lepidópteros, não de forma isolada, mas como uma alternativa no manejo integrado. A aplicação exógena de elicitores induz a emissão de voláteis, como o ácido jasmônico e seus derivados, que é capaz de atrair inimigos naturais. A indução deste ácido beneficia as plantas através de uma combinação da indução de defesas diretas e indiretas. Além dos derivados do ácido jasmônico, outros compostos podem afetar tanto pragas como inimigos naturais no campo (PINTO-ZEVALLOS, 2013).

No tabaco selvagem, Nicotiana attenuata Torr. ex S.Watson, a aplicação de jasmonato de metila (MeJA), (Z)-3-hexene-1-ol, linalol e (Z)- $\alpha$ bergamoteno incrementaram a mortalidade de ovos de Manduca sexta (Linnaeus, 1763) (Lepidoptera: Sphingidae) pelo percevejo predador Geocoris pallens Stål, 1954 (Hemiptera: Geocoridae). Além disso, a indução com linalool ou MeJA provocou a redução no índice de oviposição dessa lagarta (KESSLER \& BALDWIN, 2001).

Os voláteis produzidos após o ataque de herbívoros podem também ser utilizados na captura de insetos-praga. O salicilato de metila pode inibir a oviposição e reduzir a incidência de pragas. Por exemplo, fêmeas acasaladas de Mamestra brassicae (Linnaeus, 1758) (Lepidoptera: Noctuidae) evitam plantas de Brassica napus com dispersores de salicilato de metila (ULLAND, 2008). O uso de voláteis combinados com feromônios também pode ser uma alternativa para desenvolver atraentes mais eficientes de insetos-praga, através do sinergismo entre estes semioquímicos. O ácido jasmônico 
sintético aplicado diretamente em plantas cultivadas aumentou o parasitismo de pragas de lagartas, e quando incorporados na pasta de lanolina e aplicados perto dos ovos de uma mariposa aumentaram a predação por um inseto predador (BENGTSSON et al., 2006; REDDY; GUERRERO, 2004).

A estratégia do "empurrar-puxar", baseada em sinais visuais e olfativos, envolve a manipulação do comportamento dos insetos-praga e de seus inimigos naturais através de uma integração de estímulos que atuam para manter o cultivo protegido ou inadequado para a praga e os atraírem a uma fonte na qual serão eliminados. Além destes, o desenvolvimento de plantas transgênicas e a preparação das plantas a futuros ataques são alternativas que podem compor programas de manejo de lepidópteros (REDDY \& GUERRERO, 2004).

A maioria dos feromônios estudados são sexuais. Os lepidópteros se destacam nas pesquisas em torno do uso de semioquímicos, o que se deve principalmente a expectativa da utilização destes compostos nas estratégias de controle e monitoramento dessas pragas que atacam uma grande quantidade de culturas, destacam-se ainda os efeitos ambientais benéficos desse tipo de controle (ZARBIN et al., 2009).

A utilização destes compostos pode ser empregada no monitoramento, em armadilhas como ferramentas para detectar a presença e densidade da praga. Armadilhas com feromônio são eficazes em proporcionar um alerta rápido de incidência do inseto. Elas também são úteis para definir a distribuição dele na área e no tempo. Neste tipo de monitoramento a fonte de atração geralmente é um feromônio sexual sintético, a exemplo do produto comercial Bio Spodoptera®, para monitoramento de Spodoptera frugiperda. Na coleta em massa, o feromônio é usado como atrativo do inseto para um recipiente de contenção visando a eliminação ou diminuição do inseto-praga no cultivo. Neste método são utilizadas altas densidades de armadilhas, com o objetivo de capturar o maior número possível de indivíduos (TREMATERRA, 1997).

A técnica da confusão sexual pode ser considerado como um método de controle. A interrupção de acasalamento se baseia na interferência ou impedimento da transmissão de sinais entre os parceiros sexuais. Para confusão sexual de Pectinophora gossypiella utiliza-se o feromônio de nome comercial $\mathrm{Pb}$ Hope $\mathrm{L} \circledast$. É realizada a liberação de uma quantidade maior do produto na área em que se deseja o controle, para diminuir ou impedir os insetos de localizar seu respectivo parceiro e, dessa forma, reduzir o acasalamento e, consequentemente, sua nova geração (ZARBIN et al., 2009).

\section{Importância econômica}

A identificação dos metabólitos vegetais, aleloquímicos, pode resultar em uma fonte para desenvolvimento de moléculas inseticidas de base biológica através do fornecimento de estruturas complementares para síntese futura e como auxilio no desenvolvimento de novos locais-alvo moleculares (LAFIT et al., 2017).

O emprego de feromônios como uma das ferramentas no manejo integrado de pragas tem se consolidado e se tornado cada vez mais frequente. A expansão de formulação destes compostos está melhorando e ocorre a partir do conhecimento dos feromônios sexuais de lepidópteros para incluir feromônios e outros atrativos para uma ampla gama de insetos. Muito embora a taxa de identificação de atrativos para insetos de diversas ordens esteja aumentando (SUCKLING, 2000).

$\mathrm{O}$ uso de tecnologias relacionadas baseadas em produtos químicos voláteis podem ajudar a atender a demanda por sistemas de produção com pouco uso de insumos e baixo impacto (SUCKLING, 2000).

\section{Perspectivas futuras}

As pesquisas desenvolvidas em torno da ecologia química dos semioquímicos, tem permitido a ampliação do conhecimento destas moléculas nos campos da química, ecologia, entomologia, biologia molecular, dentre outras (PINTO-ZEVALLOS et al., 2013).

Os compostos voláteis induzidos após herbivoria não só guiam os inimigos naturais em direção à planta hospedeira da presa, como também auxiliam na mediação de diversas interações ecológicas que tem potencial para 0 desenvolvimento de novas estratégias de controle de pragas (PINTO-ZEVALLOS et al., 2013).

As pesquisas com semioquímicos estão sendo ampliadas e se destacam por poder ser utilizados na interrupção do acasalamento, antagonistas dos feromônios como inibidores da comunicação química, feromônios e voláteis à base de plantas como estratégias de atrativos para coleta em massa e push-pull. Resultados importantes foram obtidos, particularmente na interrupção do acasalamento, com redução significativa no uso de pesticidas em infestações baixas a moderadas de pragas. Culturas com 0 manejo integrado consolidado consomem mais produtos feromonais. No entanto, a produção de grandes culturas por seguir o modelo do calendário agrícola, termina por utilizar também maiores quantidades de inseticidas, sendo um desafio futuro para estes a implantação de técnicas de monitoramento para 0 melhor planejamento de medidas de controle (ZARBIN et al., 2009).

\section{Considerações finais}

O uso de semioquímicos para controle de lepidópteros se destaca por não apresentar resíduos e ter especificidade, não causando efeito deletério aos insetos que não sejam alvo, além de poder ser utilizado nos diferentes métodos como auxiliador desde o monitoramento até o controle das mariposas. 
Embora o uso esteja em constante crescimento, ainda há muita pesquisa a ser realizada sobre estes compostos, principalmente para as condições climáticas do país. O que ainda dificulta sua utilização, além do preço, é a aceitação do produtor que de forma cultural dá prioridade a outras alternativas.

Diante dos danos que os lepidópteros podem causar, principalmente nas culturas anuais que tendem a não seguir um programa de manejo integrado adequado, necessita-se de políticas públicas que promovam regras para regulamentar o uso de medidas sustentáveis, sendo os semioquímicos uma alternativa de auxiliar essa demanda.

\section{Referências}

AN, M. et al. Mathematical modelling of allelopathy: II. The dynamics of allelochemicals from living plants in the environment. Ecological Modelling, vol. 161, n. 1-2, p. 53-66, $2003 . \quad$ DOI: https://doi.org/10.1016/S0304-3800(02)00289-2

BAKTHAVATSALAM, N. Semiochemicals. In: Ecofriendly pest management for food security. Academic Press, 2016. p. 563-611. DOI: https://doi.org/10.1016/B978-0-12-803265-7.000191

BENGTSSON, M. et al. Plant volatiles mediate attraction to host and non-host plant in apple fruit moth, Argyresthia conjugella. Entomologia Experimentalis et Applicata, vol. 118, n. 1, p. 77-85, 2006. DOI: https://doi.org/10.1111/i.15707458.2006.00359.x

DICKE, M.; TAKKEN, W. (Ed.). Chemical ecology: from gene to ecosystem. Springer Science \& Business Media, 2006.

GOULART, H. F. et al. Feromônios: uma alternativa verde para o manejo integrado de pragas. Revista Virtual de Química, vol. 7, n. 4, p. 1205-1224, 2015. DOI: $\quad$ https://doi.org/10.1016/B978-0-12-8193044.00007-5

GROSS, E. M. Allelochemical reactions. 2009. DOI: https://doi.org/10.1016/B978-012370626-3.00106-X HOLOPAINEN, J. K. Multiple functions of inducible plant volatiles. Trends in plant science, vol. 9, n. 11, p. 529-533, 2004.2 DOI: https://doi.org/10.1016/j.tplants.2004.09.006

IMENES, S. D. L.; IDE, S. Principais grupos de insetos pragas em plantas de interesse econômico. O Biológico, vol. 64, n. 2, 2002

KESSLER, A.; BALDWIN, I. T. Defensive function of herbivore-induced plant volatile emissions in nature. Science, vol. 291, n. 5511, p. 2141-2144, 2001.

LATIF, S.; CHIAPUSIO, G.; WESTON, L. A. Allelopathy and the role of allelochemicals in plant defence. In: Advances in Botanical Research. Academic Press, 2017. p. 19-54. DOI: https://doi.org/10.1016/bs.abr.2016.12.001

LEAL, W. S. Mechanism of Action of Insect Pheromones and Other Semiochemicals. 2019. DOI: https://doi.org/10.1016/B978-0-12-409547-2.14735$\underline{3}$

LEAL, W. S. Pheromone reception. In: The Chemistry of Pheromones and other semiochemicals II. Springer, Berlin, Heidelberg, 2005. p. 1-36.

LUNTZ, A. J. M. Arthropod semiochemicals: mosquitoes, midges and sealice. 2003. DOI: https://doi.org/10.1042/bst0310128

MATSUI, K. Green leaf volatiles: hydroperoxide lyase pathway of oxylipin metabolism. Current opinion in plant biology, vol. 9, n. 3, p. 274-280, 2006. DOI: https://doi.org/10.1016/i.pbi.2006.03.002

PICKETT, J. A.; WADHAMS, L. J.; WOODCOCK, C. $M$. Developing sustainable pest control from chemical ecology. Agriculture, ecosystems \& environment, vol. 64 , n. 2, p. 149-156, 1997. DOI: https://doi.org/10.1016/S0167-8809(97)00033-9

PINTO-ZEVALLOS, D. M. et al. Compostos orgânicos voláteis na defesa induzida das plantas contra insetos herbívoros. Química Nova, vol. 36, n. 9, p. 1395-1405, 2013. DOI: https://doi.org/10.1590/S0100-40422013000900021

REDDY, G. VP; GUERRERO, A. Interactions of insect pheromones and plant semiochemicals. Trends in plant science, vol. 9, n. 5, p. 253-261, 2004.

https://doi.org/10.1016/i.tplants.2004.03.009

REDDY, Gadi VP; GUERRERO, Angel. New pheromones and insect control strategies. In: Vitamins \& hormones. Academic Press, 2010. p. 493-519. DOI: https://doi.org/10.1016/S0083$\underline{6729(10) 83020-1}$

RODRIGUEZ, S. A.; PINTO, O. A.; HOLLMANN, A. Interaction of semiochemicals with model lipid membranes: A biophysical approach. Colloids and Surfaces B: Biointerfaces, vol. 161, p. 413-419, 2018. DOI:

https://doi.org/10.1016/i.colsurfb.2017.11.002

SMART, L. E.; ARADOTTIR, G. I.; BRUCE, T. J. A. Role of semiochemicals in integrated pest management. In: Integrated Pest Management. Academic Press, 2014. p. 93-109. DOI: https://doi.org/10.1016/B978-0-12-398529-3.000075

SUCKLING, D. M. Issues affecting the use of pheromones and other semiochemicals in orchards. Crop protection, vol. 19, n. 8-10, p. 677-683, 2000. 
DOI: https://doi.org/10.1016/S0261-2194(00)00090$\underline{9}$

TEWARI, S. et al. Use of pheromones in insect pest management, with special attention to weevil pheromones. In: Integrated Pest Management. Academic Press, 2014. p. 141-168. DOI: https://doi.org/10.1016/B978-0-12-398529-3.00010$\underline{5}$

TREMATERRA, P. Integrated pest management of stored-product insects: practical utilization of pheromones. Anzeiger für Schädlingskunde, Pflanzenschutz, Umweltschutz, vol. 70, n. 3, p. 4144, 1997. DOI: https://doi.org/10.1007/BF01996919

TUMLINSON, J. H.; TEAL, P. E. A. Relationship of structure and function to biochemistry in insect pheromone systems. In: Pheromone biochemistry. Academic Press, 1987. p. 3-26. DOI: https://doi.org/10.1016/B978-0-12-564485-3.50006$\underline{3}$

ULLAND, S. et al. Plant volatiles activating specific olfactory receptor neurons of the cabbage moth Mamestra brassicae L. (Lepidoptera, Noctuidae). Chemical senses, vol. 33, n. 6, p. 509-522, 2008. DOI: https://doi.org/10.1093/chemse/bjn018

VILELA, E. F.; DELLA LÚCIA, T. M. C. Introdução aos semioquímicos e terminologia. Feromônios de
Insetos: Biologia, Química e Emprego no Manejo de Pragas, $2^{a}$ edição, Ribeirão Preto: Holos, p. 9-12, 2001.

YAN, Y. et al. Functional characterization of a binding protein for Type-II sex pheromones in the tea geometrid moth Ectropis obliqua Prout. Pesticide Biochemistry and Physiology, 2020. DOI: https://doi.org/10.1016/i.pestbp.2020.02.008

ZAMBOLIM, L.; CONCEIÇÃO, MZ da; SANTIAGO, T. O que engenheiros agrônomos devem saber para orientar o uso de produtos fitossanitários. UFV, Viçosa, 2003.

ZARBIN, P. H. G.; RODRIGUES, M. A. C. M.; LIMA, E. R. Feromônios de insetos: tecnologia e desafios para uma agricultura competitiva no Brasil. Química Nova, vol. 32, n. 3, p. 722-731, 2009. DOI: https://doi.org/10.1590/S0100-40422009000300016.

ZHANG, J.; WALKER, W. B.; WANG, G. Pheromone reception in moths: from molecules to behaviors. In: Progress in Molecular Biology and Translational Science. Academic Press, 2015. p. 109-128. DOI: https://doi.org/10.1016/bs.pmbts.2014.11.005 